\title{
Supporting Information for Marcromolecular Architecture and Encapsulation of the Anticancer Drug Everolimus Control the Self-Assembly of Amphiphilic Polypeptide-Containing Hybrids.
}

Anastasis Karatzas, ${ }^{\dagger}, 1$ Johannes Haataja ${ }^{\dagger}, 2$ Dimitrios Skoulas, ${ }^{l}$ Panayiotis Bilalis, ${ }^{1}$ Spyridon Varlas, ${ }^{1}$ Panagiota Apostolidi, ${ }^{1}$ Sosanna Sofianopoulou, ${ }^{3}$ Efstratios Stratikos, ${ }^{4}$ Nikolay Houbenov, ${ }^{2}$ Olli Ikkala ${ }^{2}$ and Hermis Iatrou ${ }^{*}, 1$

1. University of Athens, Department of Chemistry, Panepistimiopolis, Zografou, 15771, Athens, Greece

2. Aalto University, Department of Applied Physics, FI-00076, Aalto, Espoo, Finland

3. Hellenic Republic, Ministry of Rural Development and Food, Athens, Greece

4. National Centre for Scientific Research Demokritos, Patriarhou Gregoriou and Neapoleos 27, Agia Paraskevi 15341, Athens, Greece

\section{Synthesis of $\mathbf{N}^{(\mathrm{im})}$-Trityl-L-Histidine N-Carboxy Anhydride (Trt-His-NCA)}

Synthesis of Trt-His-NCA $\cdot \mathbf{H C l}$ salt. The synthesis of Trt-His-NCA has been presented in detail in a previous report of our group. ${ }^{1}$ Briefly, in a round-bottom flask $20.0 \mathrm{~g}$ of BOCHis(Trt)-OH(40.2 mmol) were added and dried overnight under high vacuum. THF (150 mL) was then distilled in the flask, giving a clear yellowish solution. Under continuous argon flow, the reaction flask was placed in an ice-bath and $3.25 \mathrm{~mL}$ of thionyl chloride diluted in $20 \mathrm{~mL}$ of THF (44.2 mmol) were added dropwise over a period of $10 \mathrm{~min}$. By the end of addition of thionyl chloride, the solution became yellowish and a small aliquot was withdrawn and analyzed by FTIR spectroscopy. Indication that reaction was near complete was the disappearance of corresponding carboxylic acid peak at $1710 \mathrm{~cm}^{-1}$. After 2 hours, the solution was poured into excess amount of cold $(\mathrm{Et})_{2} \mathrm{O}$ followed by precipitation of $\mathrm{Trt}-\mathrm{His}-\mathrm{NCA} \cdot \mathrm{HCl}$ salt as the major product. Finally, the solid was filtered, transferred to a round bottom-flask and then dried in vacuo (17.2 g). Recrystallization was conducted to the solid mixture, containing the $\mathrm{HCl}$ salt, free 
anhydride and the initial substrate by distilling $300 \mathrm{~mL}$ ethyl acetate under high vacuum. The suspension then was removed from the high vacuum line and placed into a water bath at $45^{\circ} \mathrm{C}$ for $1 \mathrm{~h}$, resulting in complete dissolution of the products. The solution was then cooled to $0{ }^{\circ} \mathrm{C}$, and Trt-His-NCA $\cdot \mathrm{HCl}$ salt was formed as a precipitate, which was isolated as the only product after filtration. The NCA salt was transferred to another flask and dried overnight under high vacuum (12.5 g, $28.0 \mathrm{mmol})$. The purity of Trt-His-NCA·HCl was confirmed by ${ }^{1} \mathrm{H}$ NMR and FT-IR spectroscopy. ${ }^{1} \mathrm{H} \mathrm{NMR}\left(300 \mathrm{MHz}, \mathrm{CDCl}_{3}, \delta\right.$ in ppm): 3.20-3.50 (2H, - $\mathrm{CH}_{2}$-imidazole-Trt), 4.40$4.60\left(1 \mathrm{H}, \mathrm{N}-\mathrm{CH}\left(\mathrm{CH}_{2}-\mathrm{imidazole}-\mathrm{Trt}\right)-(\mathrm{C}=\mathrm{O})\right.$ of NCA ring $), 6.75-7.50$ (15H, trityl groups), 8.20$8.30(1 \mathrm{H}, \mathrm{N}-\mathrm{CH}=\mathrm{C}$ of imidazole ring $), 8.65-8.75(1 \mathrm{H}, \mathrm{N}-\mathrm{CH}=\mathrm{N}$ of imidazole ring).FT-IR $(\mathrm{KBr})$ : $1848,1780 \mathrm{~cm}^{-1}(v \mathrm{C}=\mathrm{O}, \mathrm{s}), 1620 \mathrm{~cm}^{-1}(v \mathrm{NHCl}$ salt, $\mathrm{s}), 748,700 \mathrm{~cm}^{-1}(v=\mathrm{C}-\mathrm{H}$ out of plane bend, s).

Synthesis of Trt-His-NCA. Subsequently, EtOAc (200 mL) was distilled into the flask, the flask was then removed from the high vacuum line, filled with argon and placed in an ice-bath. At $0{ }^{\circ} \mathrm{C}, 3.5 \mathrm{~mL}$ of stoichiometric amount of distilled triethylamine $(28.0 \mathrm{mmol})$ dissolved in $50 \mathrm{~mL}$ of the same solvent were added dropwise under vigorous stirring to the reaction solution over a 1 $\mathrm{h}$ period. The resulting salt of triethylamine hydrochloride was filtered off and the filtrate was poured in $1.5 \mathrm{~L}$ of non-solvent hexane in order to precipitate and recrystallize the Trt-His-NCA. A second recrystallization occurred using a mixture of EtOAc/Hexane (1:5) solvent/non-solvent, and the white solid precipitate of Trt-His-NCA was isolated by filtration, dried overnight and stored in a glove box (11.05 g, $27.0 \mathrm{mmol}, 67 \%)$. The purity of Trt-His-NCA was confirmed by ${ }^{1} \mathrm{H}$ NMR and FT-IR spectroscopy. ${ }^{1} \mathrm{H}$ NMR (300 MHz, $\mathrm{CDCl}_{3}, \delta$ in ppm): $2.80-3.20\left(2 \mathrm{H},-\mathrm{CH}_{2}-\right.$ imidazole-Trt $), 4.40-4.60\left(1 \mathrm{H}, \mathrm{N}-\mathrm{CH}\left(\mathrm{CH}_{2}-\mathrm{imidazole}-\mathrm{Trt}\right)-(\mathrm{C}=\mathrm{O})\right.$ of NCA ring $), 6.75-7.50$ $(16 \mathrm{H}, 15 \mathrm{Hof}$ trityl groups and $1 \mathrm{H}$ of $\mathrm{N}-\mathrm{CH}=\mathrm{C}$ of imidazole ring), $7.60-7.85(1 \mathrm{H}, \mathrm{N}-\mathrm{CH}=\mathrm{N}$ of 
imidazole ring).FT-IR(KBr): $1848,1780 \mathrm{~cm}^{-1}(\nu \mathrm{C}=\mathrm{O}, \mathrm{s}), 748,700 \mathrm{~cm}^{-1}(v=\mathrm{C}-\mathrm{H}$ out of plane bend, s).

\section{Synthesis of $\varepsilon$-tert-Butyloxycarbonyl-L-Lysine N-Carboxy Anhydride (BOC-Lys-}

NCA). $\varepsilon$-tert-Butyloxycarbonyl-L-lysineN-carboxy anhydride(BOC-Lys-NCA) was synthesized according to previously reported method. ${ }^{2}$ Briefly, $\mathrm{N}^{\alpha}, \mathrm{N}^{\varepsilon}$-di-(tert-butoxycarbonyl)-L-lysine was added into a round-bottom flask, placed on the vacuum line and dried overnight. Then EtOAc was distilled into the flask, followed by argon insertion in order to reach atmospheric pressure and by addition of triphosgene. The mixture was left to react for $10 \mathrm{~min}$. Triethylamine diluted in dry EtOAc was subsequently added dropwise, and the solution was immersed in an ice-water bath for $6 \mathrm{~h}$. The precipitate was filtered, in order to remove the $\mathrm{HCl}$ salt of triethylamine, the clear solution was immersed in an ice bath, and the NCA was extracted with Milli-Q water repeatedly, until neutral $\mathrm{pH}$ of the aqueous phase was achieved. The obtained BOC-Lys-NCA was recrystallized three times under high vacuum in a custom-made apparatus using an ethyl acetate/hexane (1/5 v/v) mixture at $-20^{\circ} \mathrm{C}$. The purified product of BOC-Lys-NCA was then dried under vacuum and stored in a glove box. The purity of the product was confirmed by ${ }^{1} \mathrm{H}$ NMR and FT-IR spectroscopy. ${ }^{1} \mathrm{H}$ NMR (300 MHz, $\mathrm{CDCl}_{3}, \delta$ in ppm): 1.00-1.60 (13H, 9Hof BOC group $-\mathrm{C}\left(\mathrm{CH}_{3}\right)_{3}, 4 \mathrm{Hof}-\mathrm{HN}-$ $\left.\mathrm{CH}_{2}-\mathrm{CH}_{2}-\mathrm{CH}_{2}-\mathrm{CH}_{2}-\right), \quad 1.60-2.20\left(2 \mathrm{H},-\mathrm{HN}-\mathrm{CH}_{2}-\mathrm{CH}_{2}-\mathrm{CH}_{2}-\mathrm{CH}_{2}-\right), 3.00-3.30(2 \mathrm{H},-\mathrm{HN}-$ $\left.\mathrm{CH}_{2}-\mathrm{CH}_{2}-\mathrm{CH}_{2}-\mathrm{CH}_{2}-\right), 4.20-4.40(1 \mathrm{H}, \mathrm{N}-\mathrm{CH}-(\mathrm{C}=\mathrm{O})), 4.40-5.00(1 \mathrm{H},-\mathrm{CH}-\mathrm{NH}-(\mathrm{C}=\mathrm{O})$ of NCA ring), 6.80-7.20 (1H, $-\mathrm{CH}_{2}-\mathrm{NH}-(\mathrm{C}=\mathrm{O})$ of $\varepsilon$-amine).FT-IR $(\mathrm{KBr}): 2650 \mathrm{~cm}^{-1}(v-\mathrm{CH}, \mathrm{BOC}$ group, s), $1848,1780 \mathrm{~cm}^{-1}(v \mathrm{C}=\mathrm{O}$, NCA ring, $\mathrm{s}), 1690 \mathrm{~cm}^{-1}(v \mathrm{C}=\mathrm{O}$, BOC group, s). Characterization details have been reported in a previous study of our group. ${ }^{1}$ 
Synthesis of $\boldsymbol{\gamma}$-Benzyl-L-Glutamate N-Carboxy Anhydride (BLG-NCA). The NCA of $\gamma$-benzyl-L-glutamate (BLG-NCA) was synthesized according to a previously reported method. ${ }^{1}$ Briefly, $\gamma$-benzyl-L-glutamate was suspended in dry EtOAc followed by addition of appropriate amount of triphosgene. The mixture was heated at $70{ }^{\circ} \mathrm{C}$ until the solution became clear, indicating the formation of the BLG-NCA. The solvent was distilled off under high vacuum, and fresh dry EtOAc was distilled in the flask to dissolve the crude BLG-NCA, followed by removal of the solvent by distillation. This procedure was repeated twice in order to remove the excess triphosgene that sublimes under high vacuum. The unreacted species, such as free amino acid along with the $\mathrm{HCl}$ salts of the amino acid produced during the synthesis, were removed by extraction with an alkali solution in water. The resulted BLG-NCA was further purified by three recrystallizations from dry EtOAc/hexane $(1 / 5 \mathrm{v} / \mathrm{v})$ mixture under high vacuum at $-20{ }^{\circ} \mathrm{C}$. The purified product of BLG-NCA was then dried under vacuum and stored in a glove box (65\% yield). The purity of BLG-NCA was confirmed by ${ }^{1} \mathrm{H}$ NMR and FT-IR spectroscopy. ${ }^{1} \mathrm{H}$ NMR (300 MHz, $\mathrm{CDCl}_{3}, \delta$ in ppm): 2.00-2.50(2H, $\left.-\mathrm{CH}-\mathrm{CH}_{2}-\mathrm{CH}_{2}-(\mathrm{C}=\mathrm{O})\right), 2.50-2.70\left(2 \mathrm{H},-\mathrm{CH}-\mathrm{CH}_{2}-\right.$ $\left.\mathrm{CH}_{2}-(\mathrm{C}=\mathrm{O})\right), 4.30-4.50(1 \mathrm{H}, \mathrm{N}-\mathrm{CH}-(\mathrm{C}=\mathrm{O})), 5.00-5.30\left(2 \mathrm{H}\right.$, phenyl- $\left.\mathrm{CH}_{2}-\mathrm{O}-(\mathrm{C}=\mathrm{O})\right), 6.40-6.70$ $\left(1 \mathrm{H},-\mathrm{CH}_{2}-\mathrm{NH}-(\mathrm{C}=\mathrm{O})\right.$ of the NCA ring), $7.20-7.60$ (5H of phenyl group).FT-IR (KBr): 1848 , $1780 \mathrm{~cm}^{-1}(v \mathrm{C}=\mathrm{O}, \mathrm{NCA}$ ring, $\mathrm{s}), 1738 \mathrm{~cm}^{-1}(v \mathrm{C}=\mathrm{O}$, ester, $\mathrm{s}), 748,700 \mathrm{~cm}^{-1}(v=\mathrm{C}-\mathrm{H}$ out of plane bend, s). Characterization details have been reported in a previous study of our group. ${ }^{1}$ 


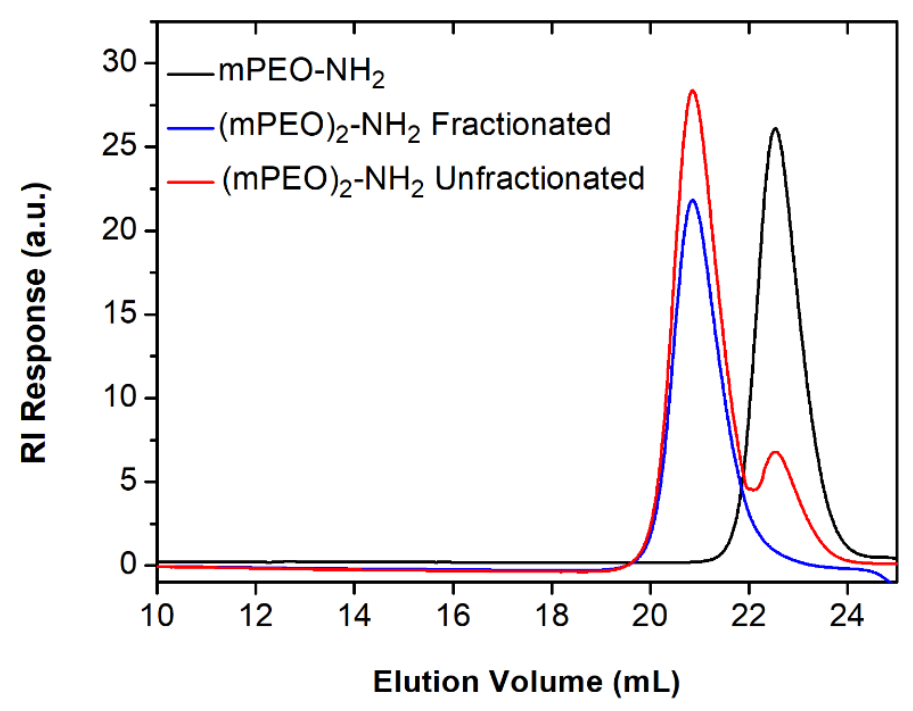

Figure S1. SEC eluograms of linear mPEO-NH 2 (black trace) and two-armed (mPEO) ${ }_{2}-\mathrm{NH}_{2}$ macroinitiator before (red trace) and after (blue trace) fractionation obtained using $0.10 \%$ TFA (v/v) solution of water/acetonitrile $(60 / 40 \mathrm{v} / \mathrm{v})$ as the eluent at a flow rate of $0.8 \mathrm{mLmin}^{-1}$ at $35^{\circ} \mathrm{C}$.

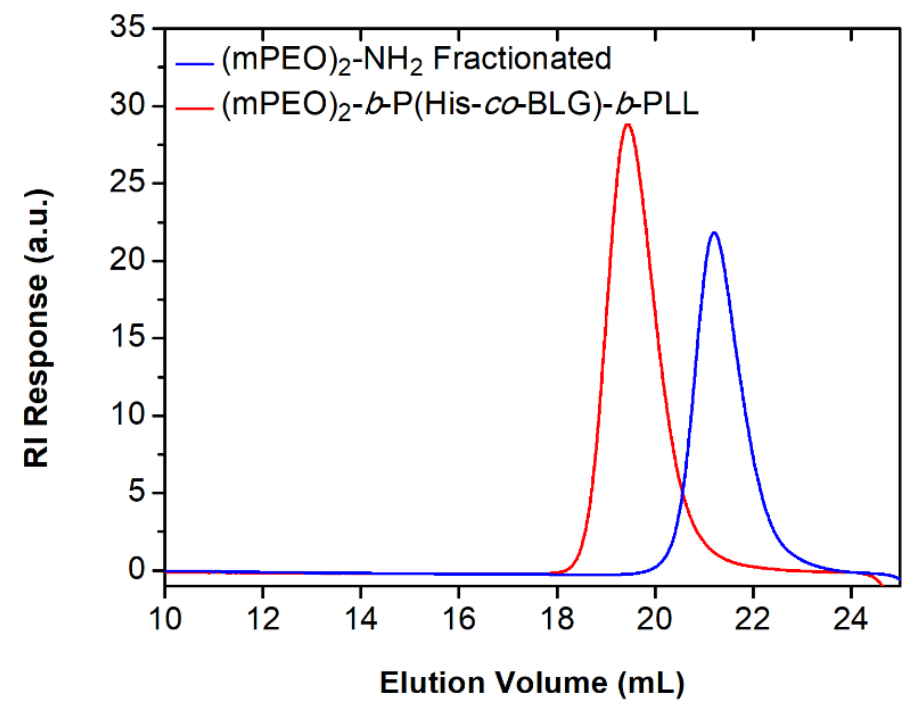

Figure S2. SEC eluograms of the two-armed $(\mathrm{mPEO})_{2}-\mathrm{NH}_{2}$ macroinitiator and the final protected hybrid (mPEO) $2-b$-P(His-co-BLG)- $b$-PLL triblock terpolypeptide with $7.0 \times 10^{3} \mathrm{gmol}^{-1}$ of the PLL block obtained using a $0.1 \mathrm{M} \mathrm{LiBr}$ in DMF solution as the eluent at a flow rate of $1 \mathrm{~mL}$ $\min ^{-1}$ at $60{ }^{\circ} \mathrm{C}$. 


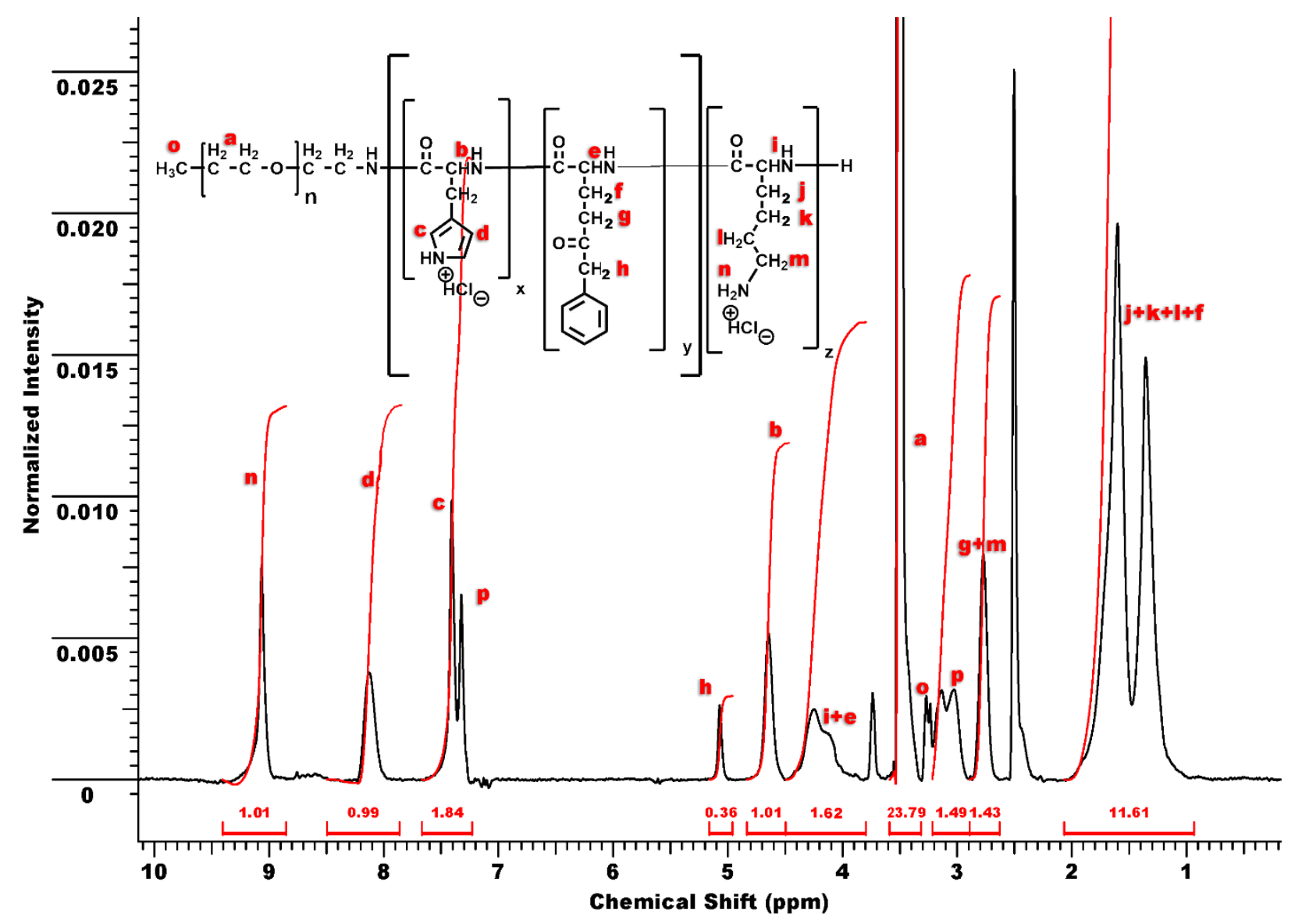

Figure S3. ${ }^{1} \mathrm{H}$ NMR spectrum of the 3-miktoarm star terpolypeptide $\mathrm{S} 7$ obtained in $\mathrm{D}_{2} \mathrm{O}$ with a few drops of $\mathrm{DCl}$.

\section{Polymer Synthesis}

All polymers were synthesized by ring-opening polymerization (ROP) using high vacuum techniques according to the general synthetic procedure described below. ${ }^{3,4}$ The polymerization was performed in a custom-made apparatus equipped with a high vacuum stopcock $(\mathrm{H})$ for periodic degassing of the solution (release of the produced $\mathrm{CO}_{2}$ ) and a magnetic stir bar covered 
with glass (D), shown in Scheme 9. The synthesis of the linear and star hybrid terpolypeptides with molecular weight of PLL=7.0 × $10^{3} \mathrm{~g} / \mathrm{mol}$ will be described.

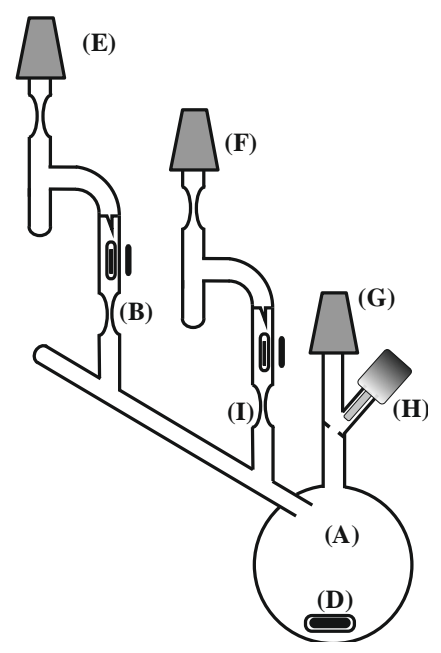

Scheme S1. The custom-made apparatus used for the synthesis of the linear as well as the 3miktoarm star amphiphilic hybrid terpolypeptides.

The apparatus was initially attached to the high vacuum line through the ground joint $(\mathrm{G})$ and was degassed and flame-dried several times. Then, it was transferred to the glove box and 300 $\mathrm{mg}\left(3.0 \times 10^{-3} \mathrm{mmol}\right)$ of either $\mathrm{mPEO}-\mathrm{NH}_{2}$ or $(\mathrm{mPEO})_{2}-\mathrm{NH}_{2}$ macroinitiator was added to the flask (A) and dried overnight under high vacuum. Subsequently, $150 \mathrm{~mL}$ of highly dry benzene were distilled to the apparatus resulting in dissolution of the macroinitiator. The solution was stirred for 2 hours and then benzene was distilled off to dryness overnight (traces of water were azeotropically distilled). Subsequently, $30 \mathrm{~mL}$ of highly pure DMF were distilled followed by dissolution of the macroinitiator. The apparatus was inserted again in the glove box, and a mixture of Trt-His-NCA and BLG-NCA(molar feed ratio of Trt-His-NCA/BLG NCA=38/7) was added in the side-ampoule equipped with a ground joint and a constriction (E and B). The apparatus was attached to the high vacuum line through the ground joint of the side ampoule containing $480 \mathrm{mg}$ of Trt-His-NCA and 
$55 \mathrm{mg}$ of BLG-NCA, degassed, followed by distillation of $5 \mathrm{~mL}$ of highly pure DMF for NCA dissolution. The apparatus was then removed from the vacuum line trough heat sealing of corresponding ground joint constriction. After the complete dissolution of Trt-His-NCA and BLGNCA, the solution of the NCAs was added by rupture of the break-seal of the ampoule, and the reaction mixture was vigorously stirred at room temperature leading to the initiation of the polymerization process. The consumption of the monomers was monitored by FT-IR spectroscopy through removal of an aliquot of the solution in the glove box. Periodically, the polymerization solution was degassed to remove the $\mathrm{CO}_{2}$ produced during ROP of NCAs. After completion of the polymerization (7 days), a small aliquot of the diblock terpolymer was collected in the glove box for further characterization. Subsequently, $448 \mathrm{mg}$ of BOC-Lys-NCA were added to the second side ampoule (F and I), followed by distillation of $5 \mathrm{~mL}$ of DMF. After the dissolution of the solid BOC-Lys-NCA, the solution was added to the main reactor, and the polymerization of lysine started immediately. The polymerization lasted for 3 days.

Finally, the obtained polymer was precipitated in excess diethylether and dried under high vacuum (1.10 g, 96\% yield). Subsequently, it was suspended in $\mathrm{CH}_{2} \mathrm{Cl}_{2}(20 \% \mathrm{w} / \mathrm{v})$ and an equal volume of trifluoroacetic acid (TFA) was added. The obtained triblock quarterpolymer was completely dissolved and was stirred for $1 \mathrm{~h}$ at room temperature to be deprotected, resulting in a yellowish-light brown solution. An equimolar amount of triethyl silane was then added (with respect to the number of His monomeric units) in order to bind the free trityl-groups preventing them from reattachment to the His units. At the equilibrium point, the solution turned colorless. The solution was poured in excess diethylether, and the precipitated white solid was filtered and dried. The obtained polymer was subsequently dissolved in Milli-Q water at $\mathrm{pH} \sim 5$ (adjusted with a dilute aqueous solution of $\mathrm{HCl})$, and was dialyzed $(\mathrm{MWCO}=3500 \mathrm{Da})$ against $2 \mathrm{~L}$ of Milli-Q 
water with $\mathrm{pH} \sim 5$ (adjusted with a dilute aqueous solution of $\mathrm{HCl}$ ) four times and two times in pure Milli-Q water. Finally, the polymer solution was lyophilized to afford the corresponding fully deprotected polymer as a white powder $(550 \mathrm{mg}, 77 \%$ yield).

The same experimental procedure of deprotection was followed for the aliquot of diblock terpolymer mPEO- $b$-P(Trt-His-co-BLG) and (mPEO) $)_{2}-b$-P(Trt-HIS-co-BLG) for characterization by ${ }^{1} \mathrm{H}$ NMR and FT-IR spectroscopy and size exclusion chromatography.

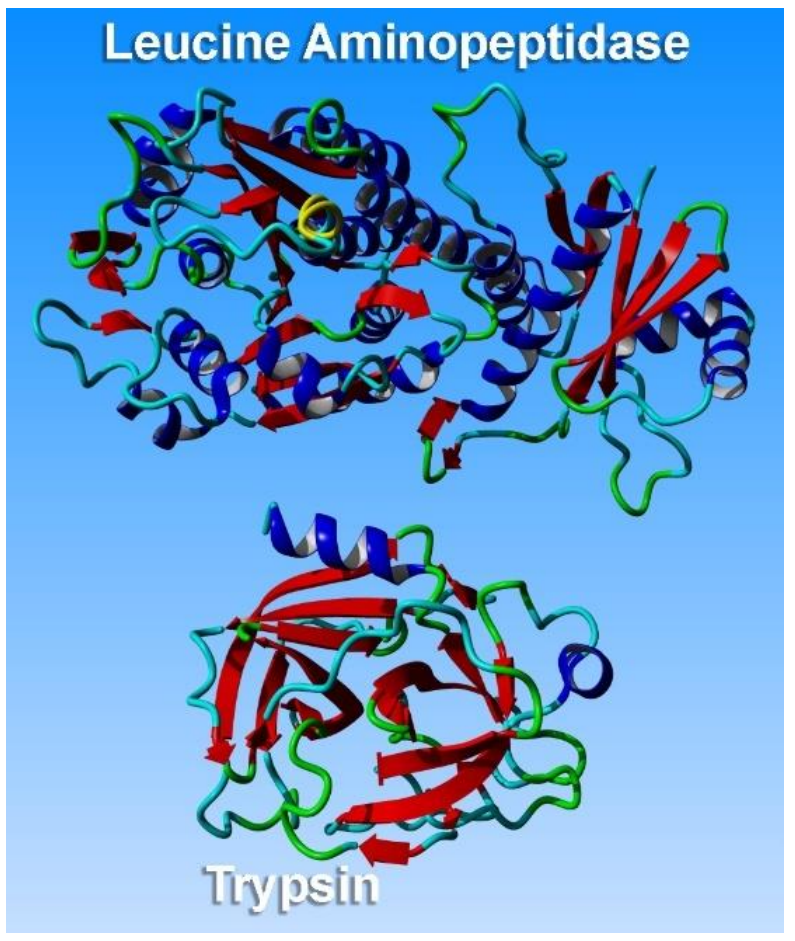

Scheme S2.Tertiary structure of the enzymes LAP and trypsin utilized for polymer degradation studies herein.

\section{DLS Size Distribution Data.}

Below we give the DLS data of the empty polymers at $\mathrm{pH}=7.4,6.5$ and 5.0. 


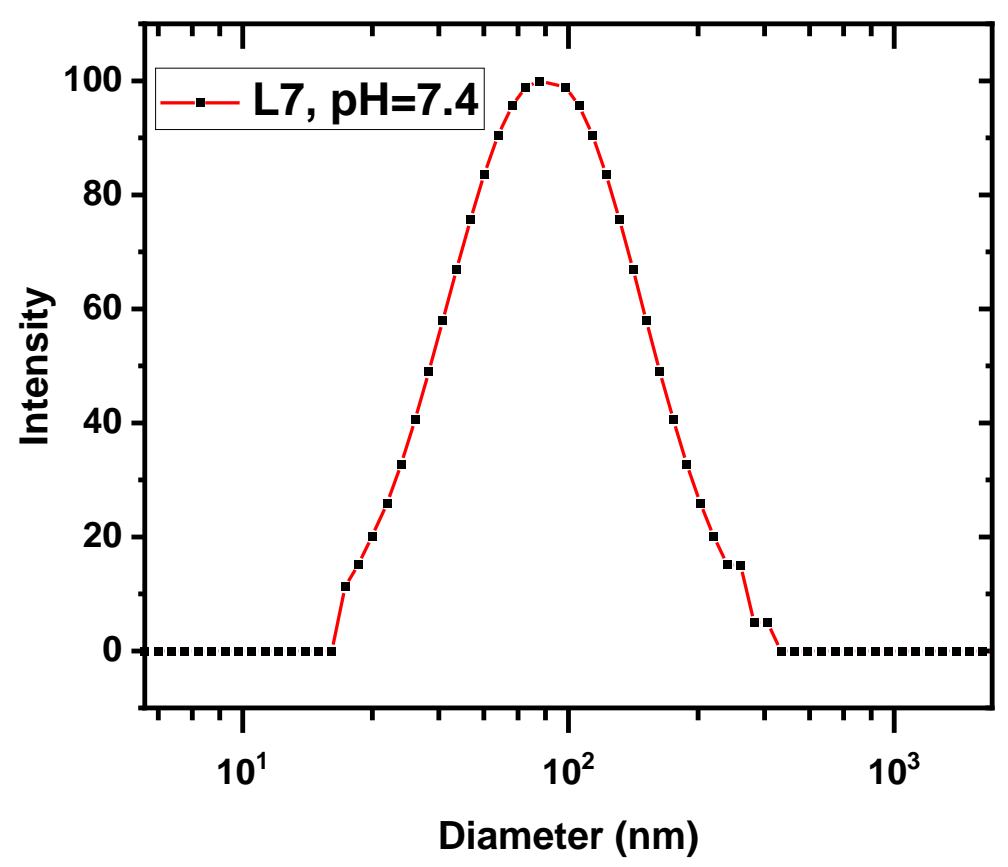

Figure S4: DLS size distribution at $90^{\circ}$ scattering angle of aggregates formed by the polymer L7 at $\mathrm{pH}=7.4$.

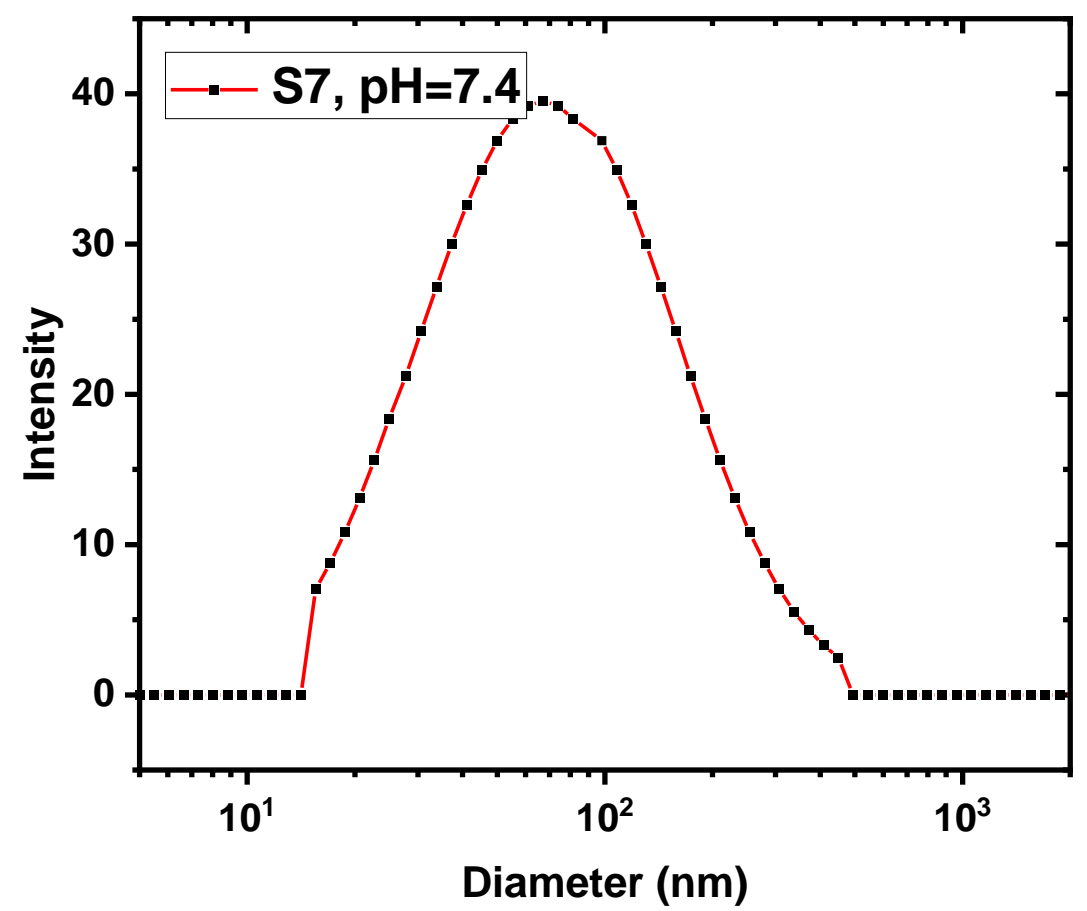

Figure S5: DLS size distribution at $90^{\circ}$ scattering angle of aggregates formed by the polymer S7 at $\mathrm{pH}=7.4$. 


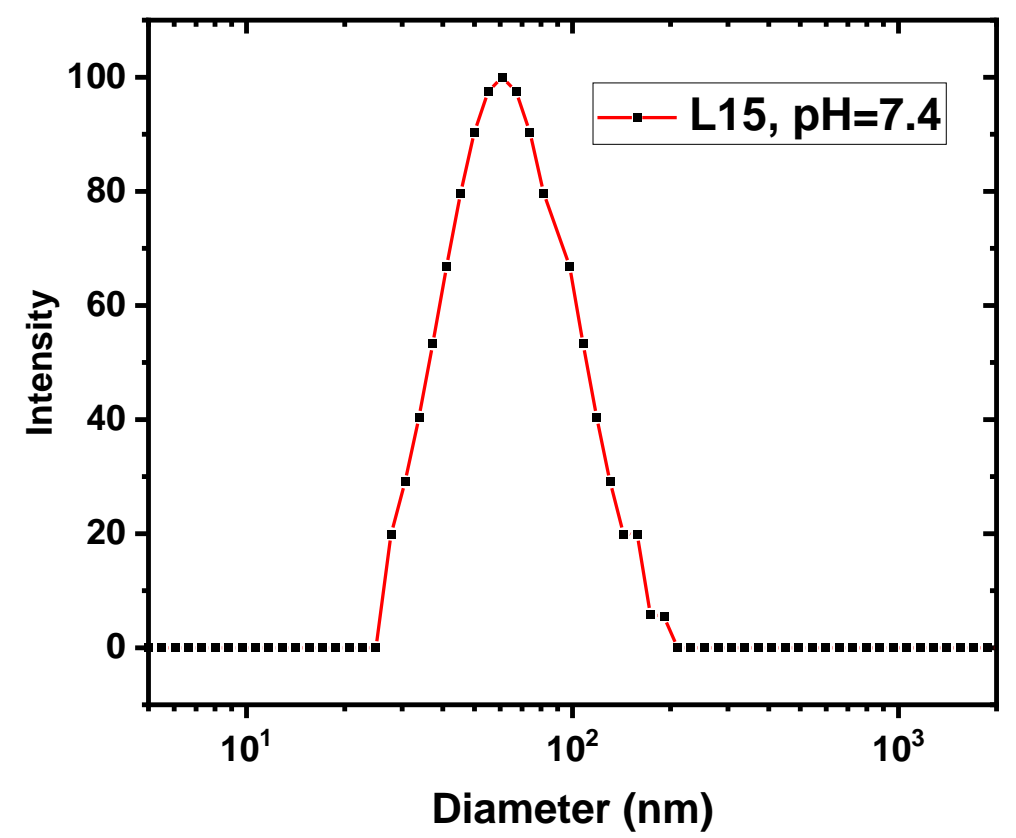

Figure S6: DLS size distribution at $90^{\circ}$ scattering angle of aggregates formed by the polymer L15 at $\mathrm{pH}=7.4$.

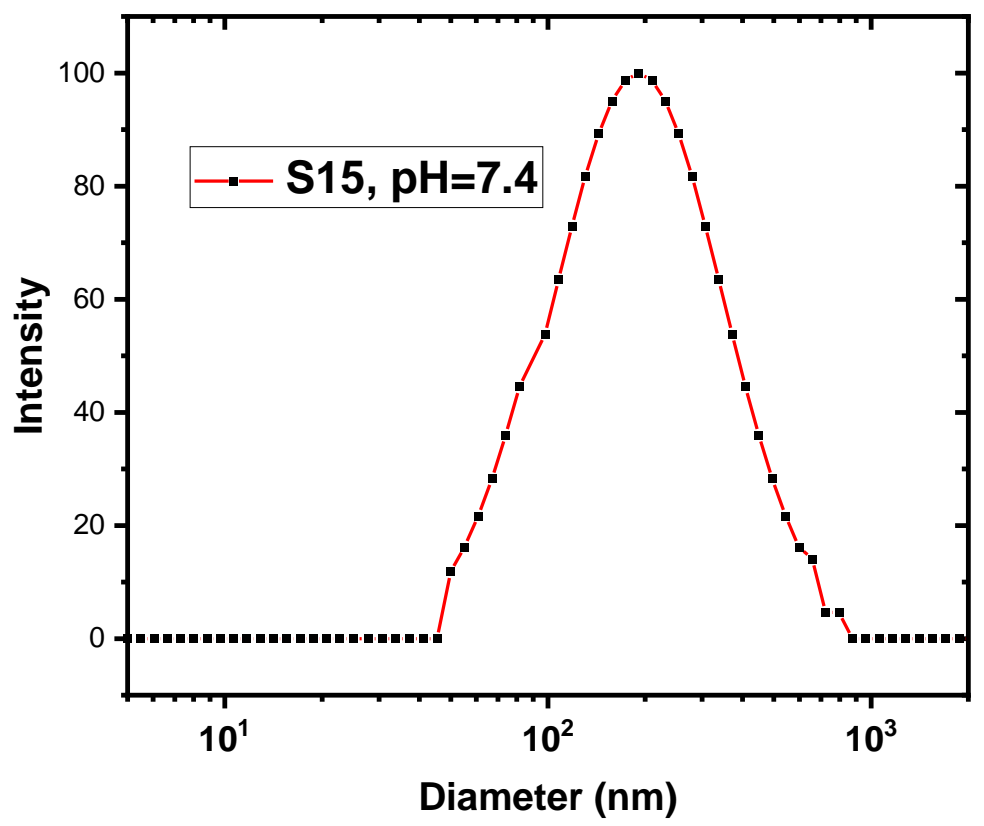

Figure S7: DLS size distribution at $90^{\circ}$ scattering angle of aggregates formed by the polymer S15 at $\mathrm{pH}=7.4$. 


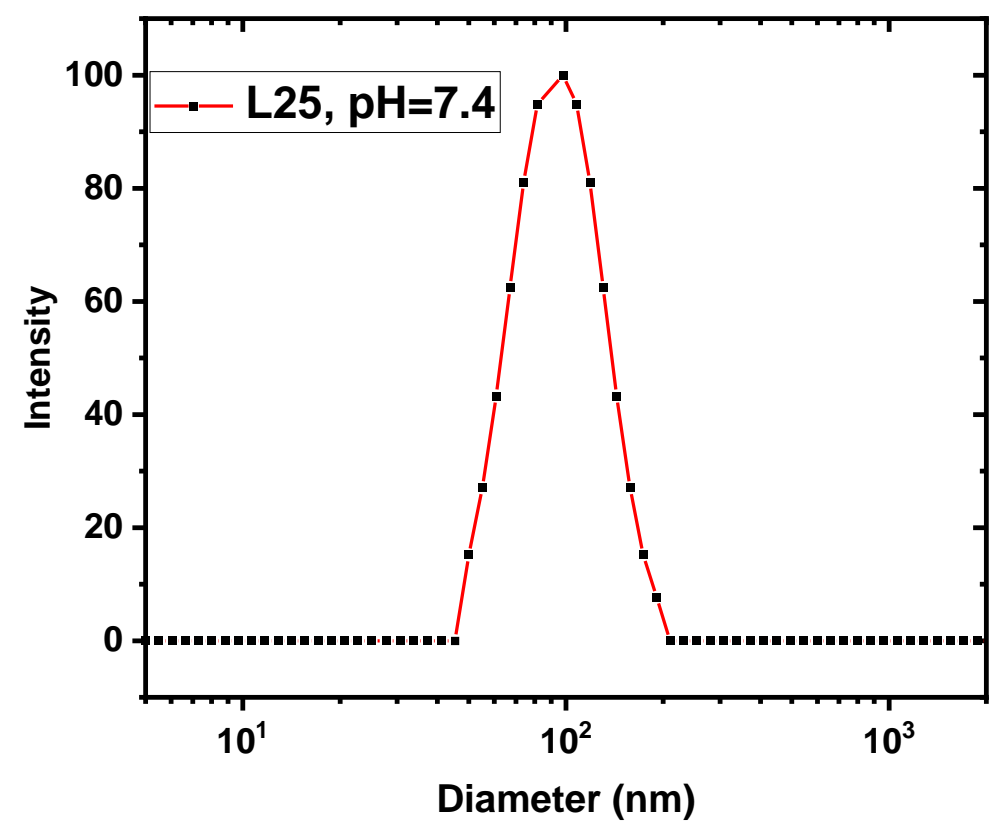

Figure S8: DLS size distribution at $90^{\circ}$ scattering angle of aggregates formed by the polymer L25 at $\mathrm{pH}=7.4$.

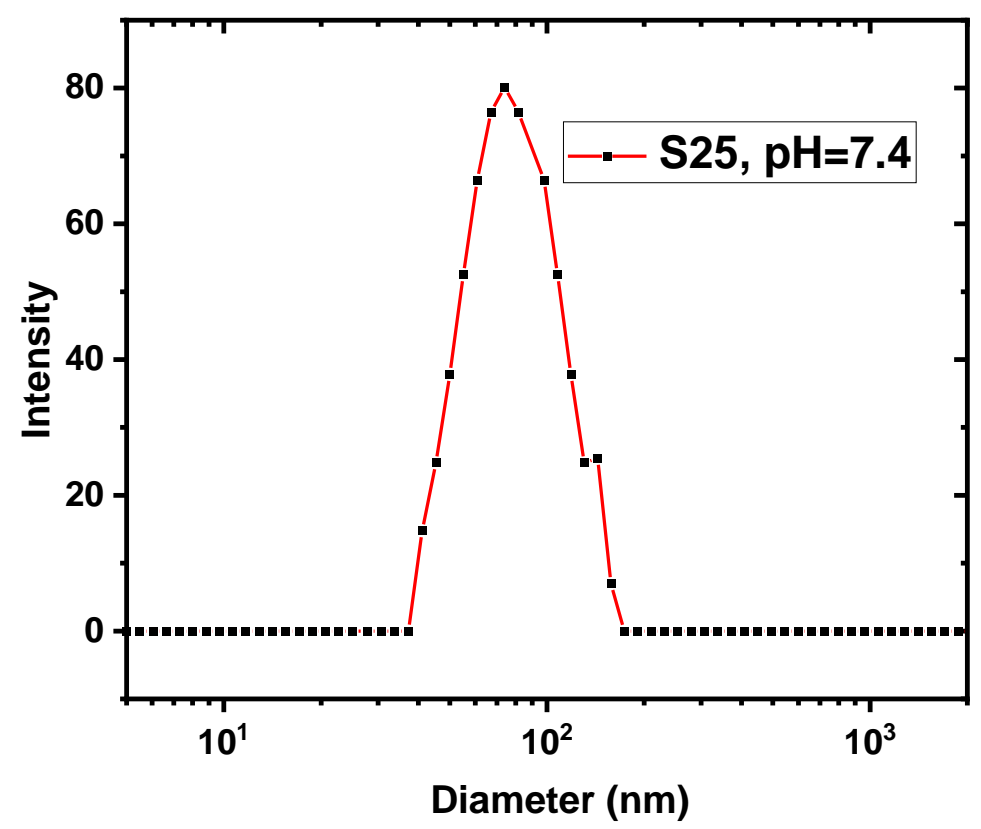

Figure S9: DLS size distribution at $90^{\circ}$ scattering angle of aggregates formed by the polymer S25 at $\mathrm{pH}=7.4$. 


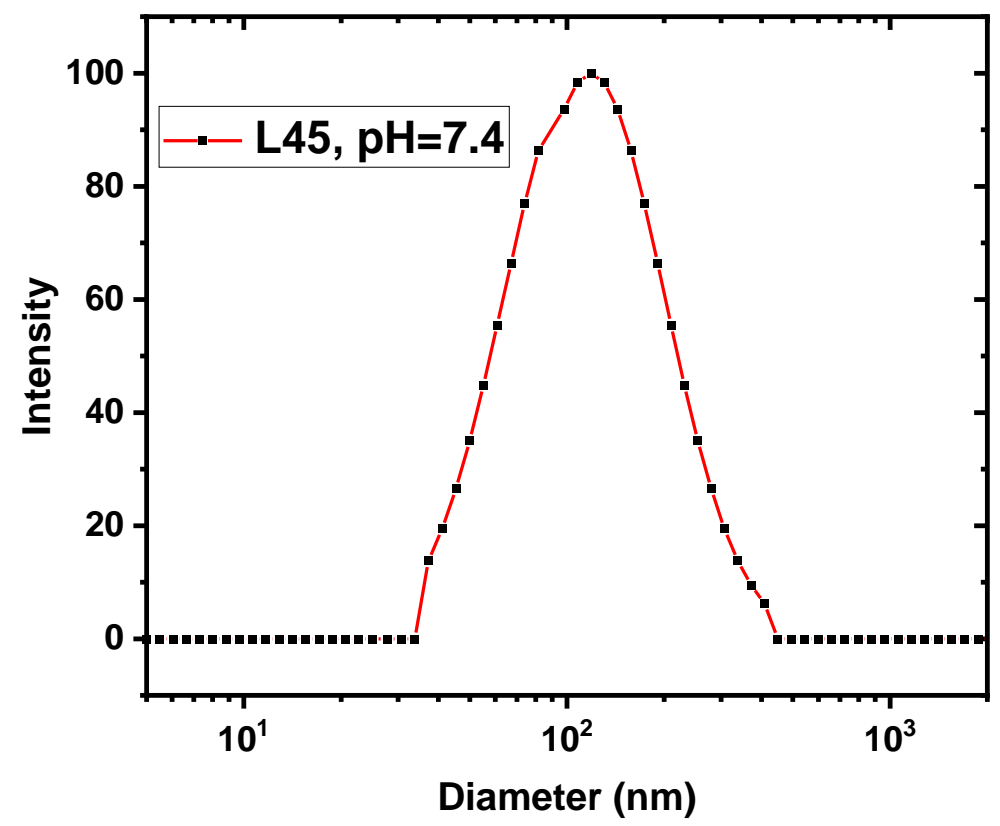

Figure S10: DLS size distribution at $90^{\circ}$ scattering angle of aggregates formed by the polymer $\mathrm{L} 45$ at $\mathrm{pH}=7.4$.

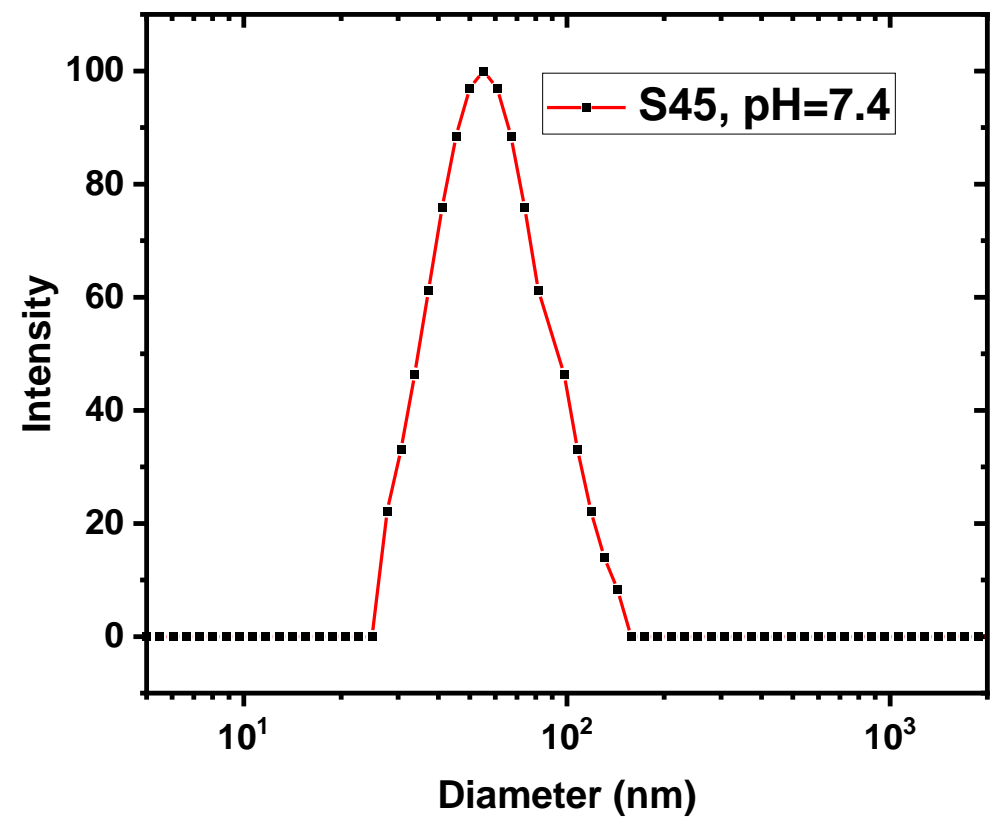

Figure S11: DLS size distribution at $90^{\circ}$ scattering angle of aggregates formed by the polymer $\mathrm{S} 45$ at $\mathrm{pH}=7.4$. 


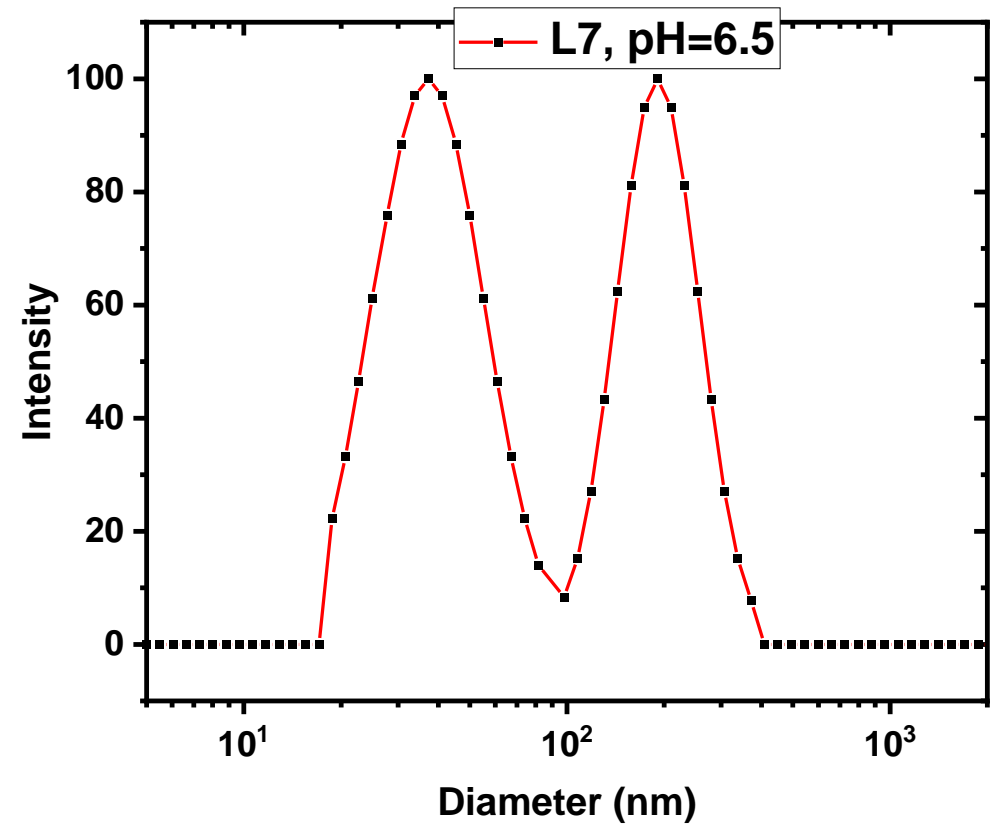

Figure S12: DLS size distribution at $90^{\circ}$ scattering angle of aggregates formed by the polymer L7 at $\mathrm{pH}=6.5$.

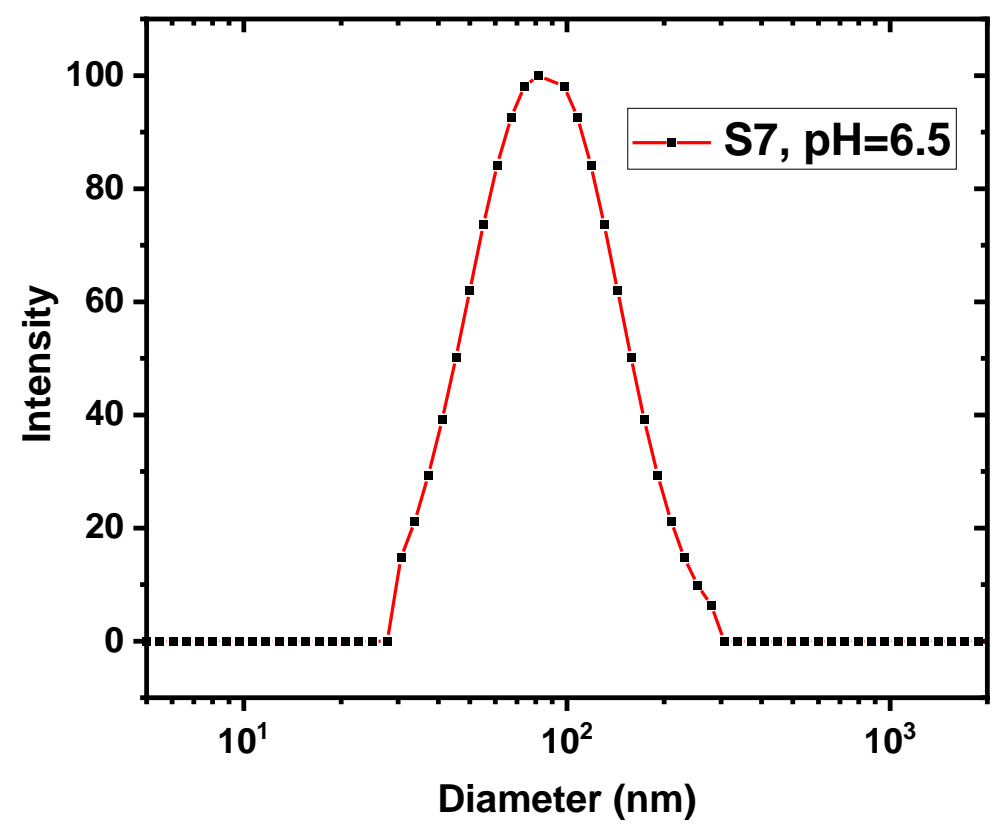

Figure S13: DLS size distribution at $90^{\circ}$ scattering angle of aggregates formed by the polymer S7 at $\mathrm{pH}=6.5$. 


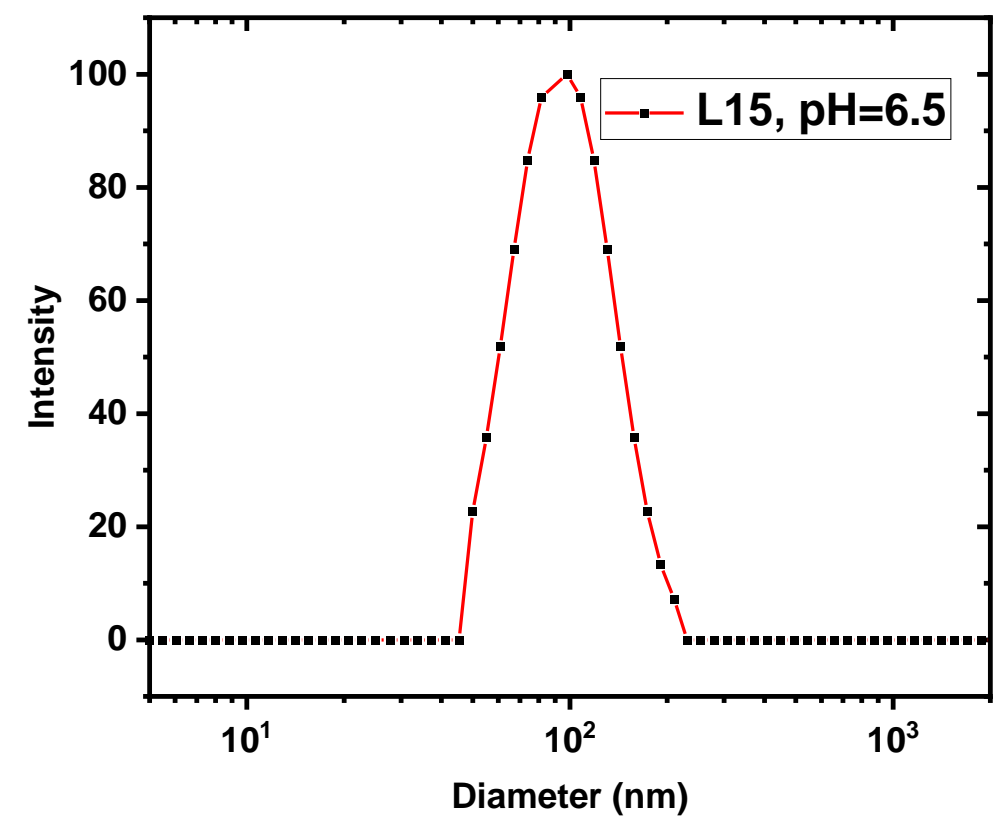

Figure S14: DLS size distribution at $90^{\circ}$ scattering angle of aggregates formed by the polymer $\mathrm{L} 15$ at $\mathrm{pH}=6.5$.

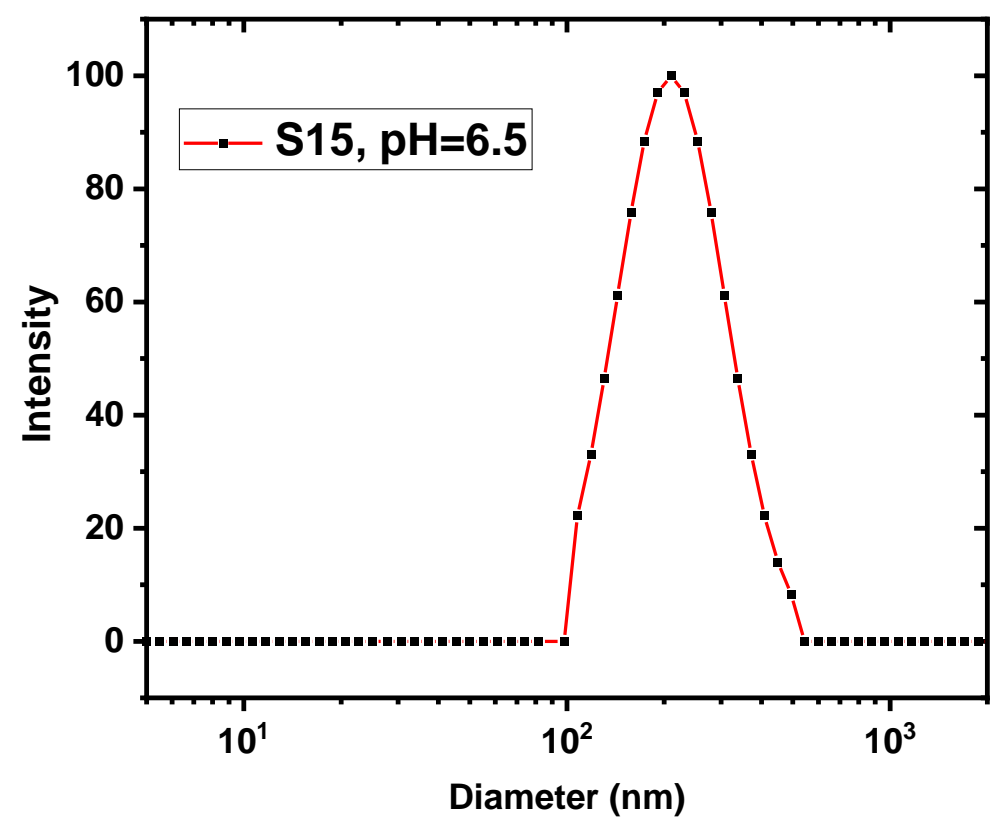

Figure S15: DLS size distribution at $90^{\circ}$ scattering angle of aggregates formed by the polymer $\mathrm{L} 15$ at $\mathrm{pH}=6.5$. 


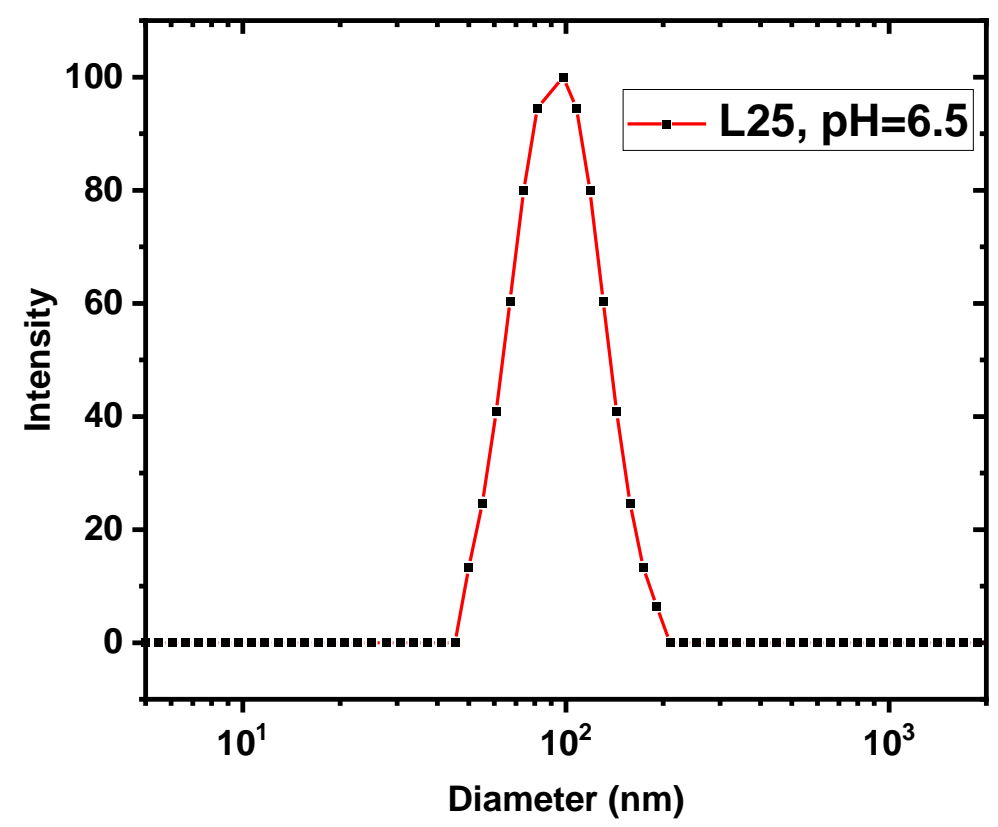

Figure S16: DLS size distribution at $90^{\circ}$ scattering angle of aggregates formed by the polymer $\mathrm{L} 25$ at $\mathrm{pH}=6.5$.

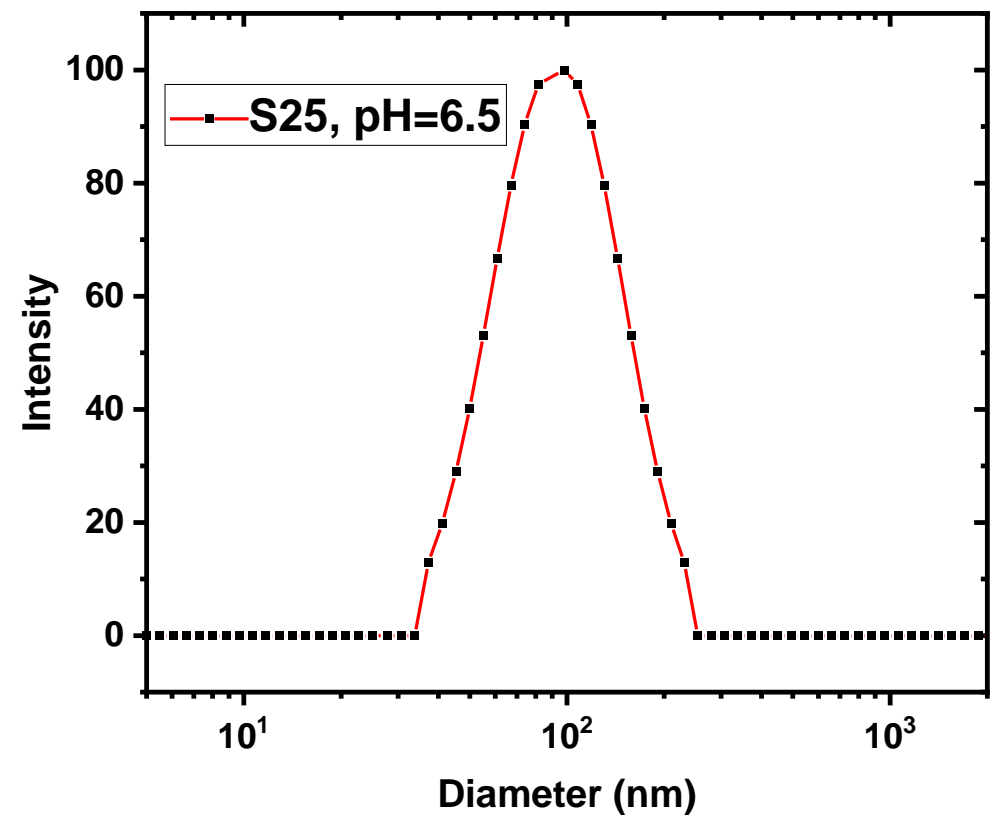

Figure S17: DLS size distribution at $90^{\circ}$ scattering angle of aggregates formed by the polymer $\mathrm{S} 25$ at $\mathrm{pH}=6.5$. 


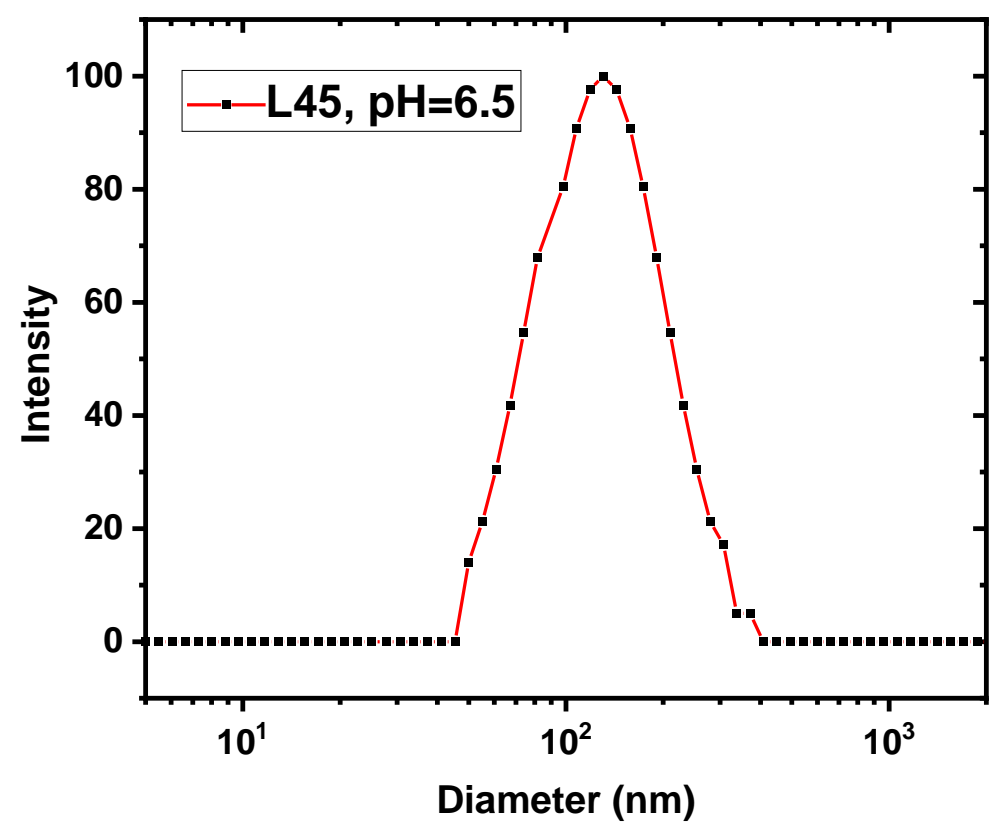

Figure S18: DLS size distribution at $90^{\circ}$ scattering angle of aggregates formed by the polymer $\mathrm{L} 45$ at $\mathrm{pH}=6.5$.

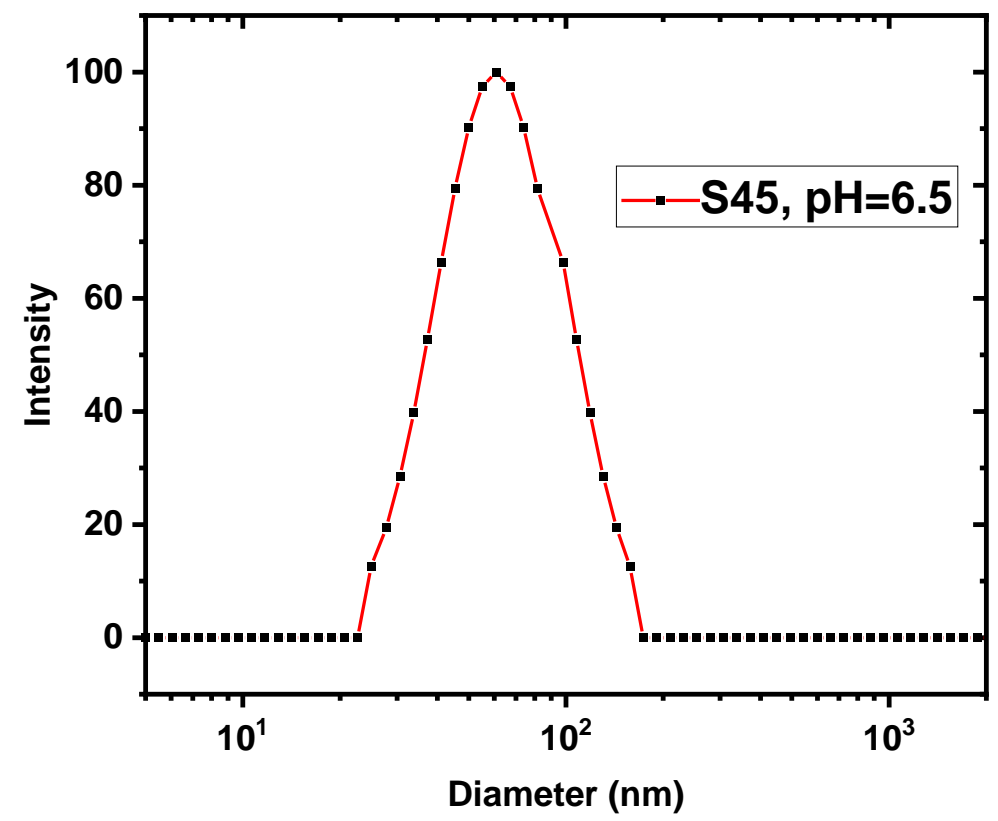

Figure S19: DLS size distribution at $90^{\circ}$ scattering angle of aggregates formed by the polymer $\mathrm{S} 45$ at $\mathrm{pH}=6.5$. 


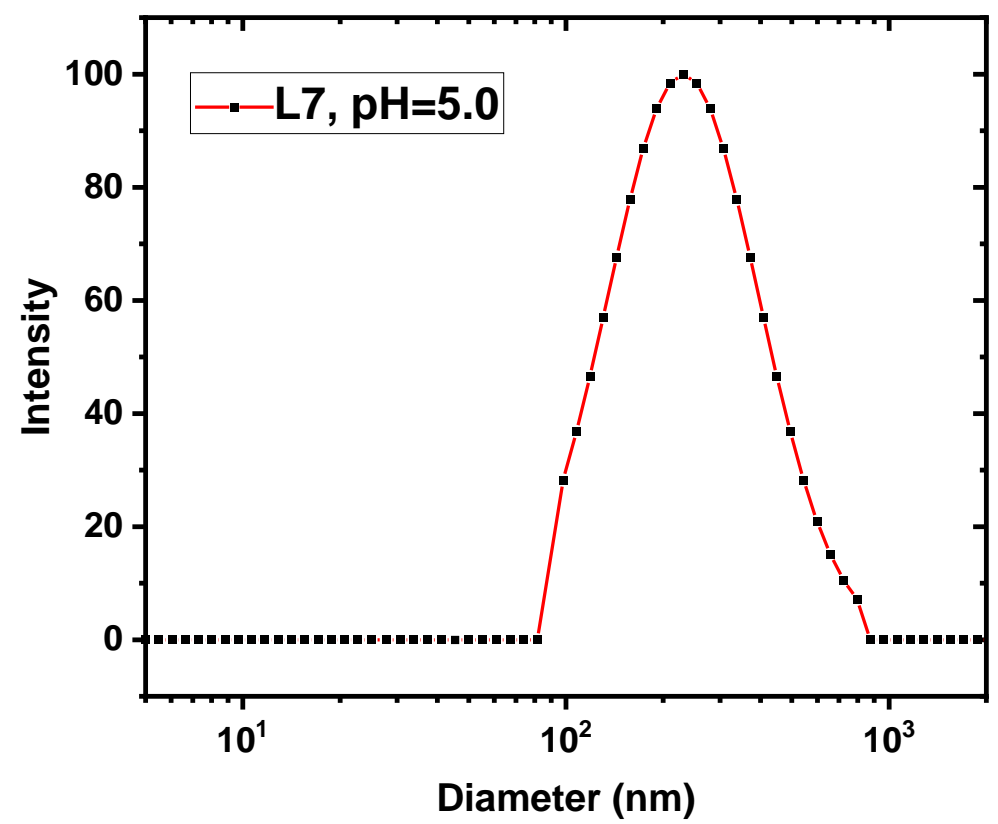

Figure S20: DLS size distribution at $90^{\circ}$ scattering angle of aggregates formed by the polymer L7 at $\mathrm{pH}=5.0$.

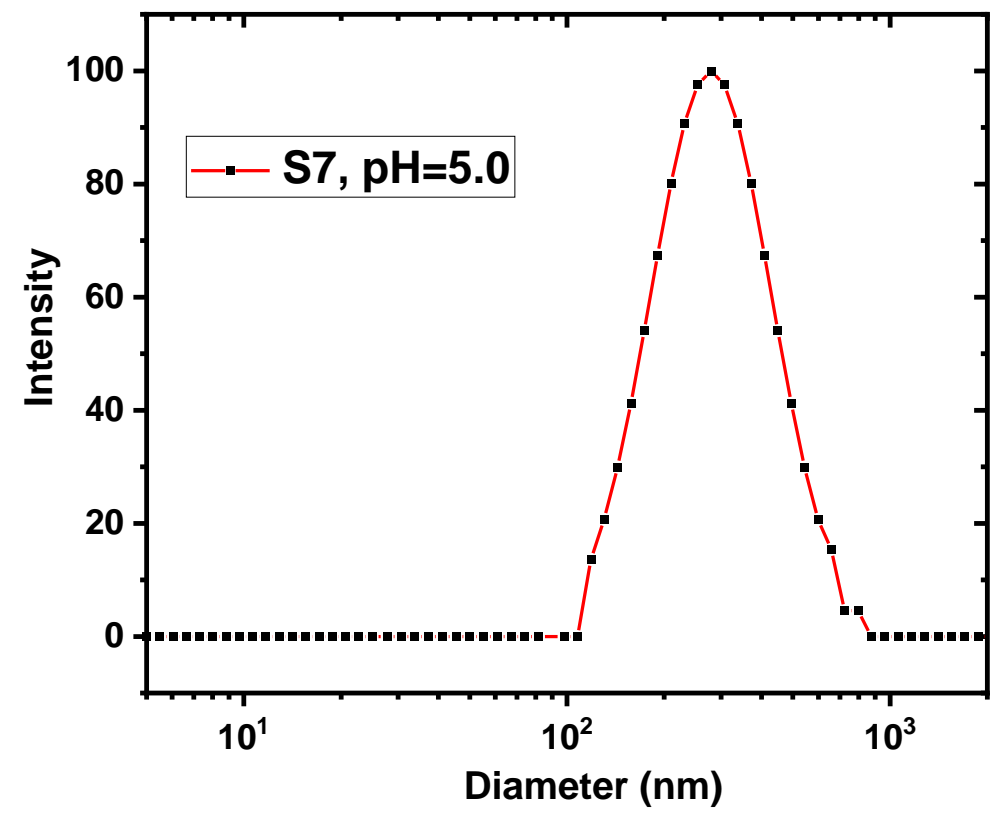

Figure S21: DLS size distribution at $90^{\circ}$ scattering angle of aggregates formed by the polymer S7 at $\mathrm{pH}=5.0$. 


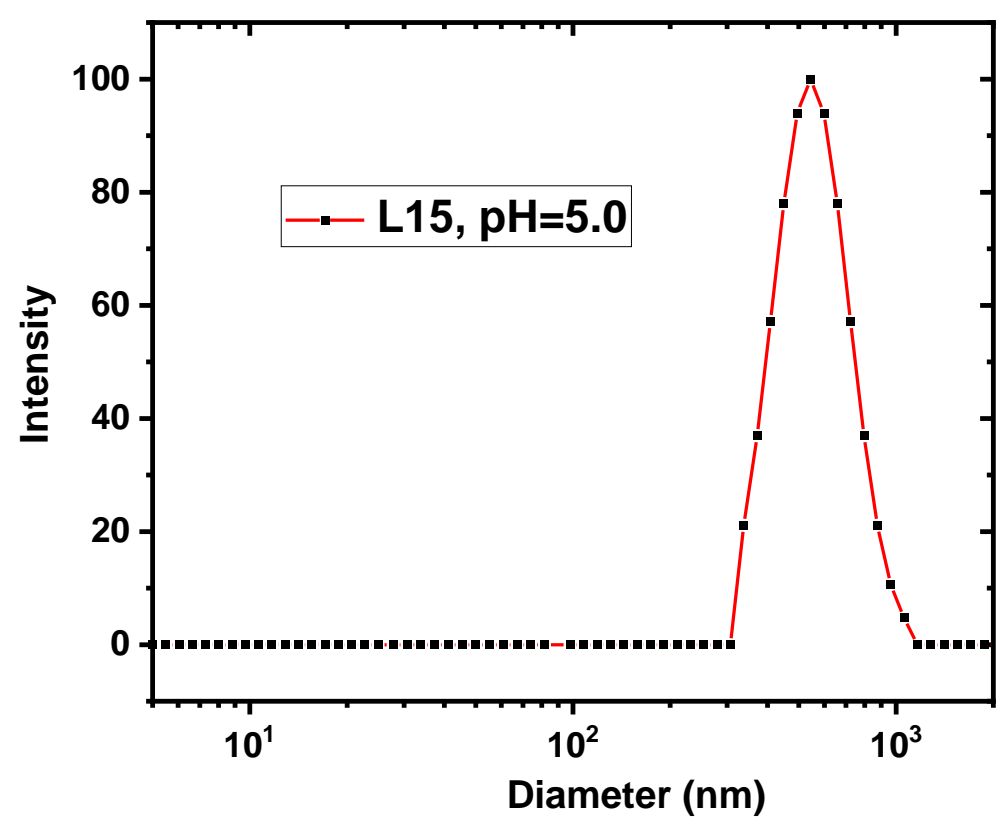

Figure S22: DLS size distribution at $90^{\circ}$ scattering angle of aggregates formed by the polymer $\mathrm{L} 15$ at $\mathrm{pH}=5.0$.

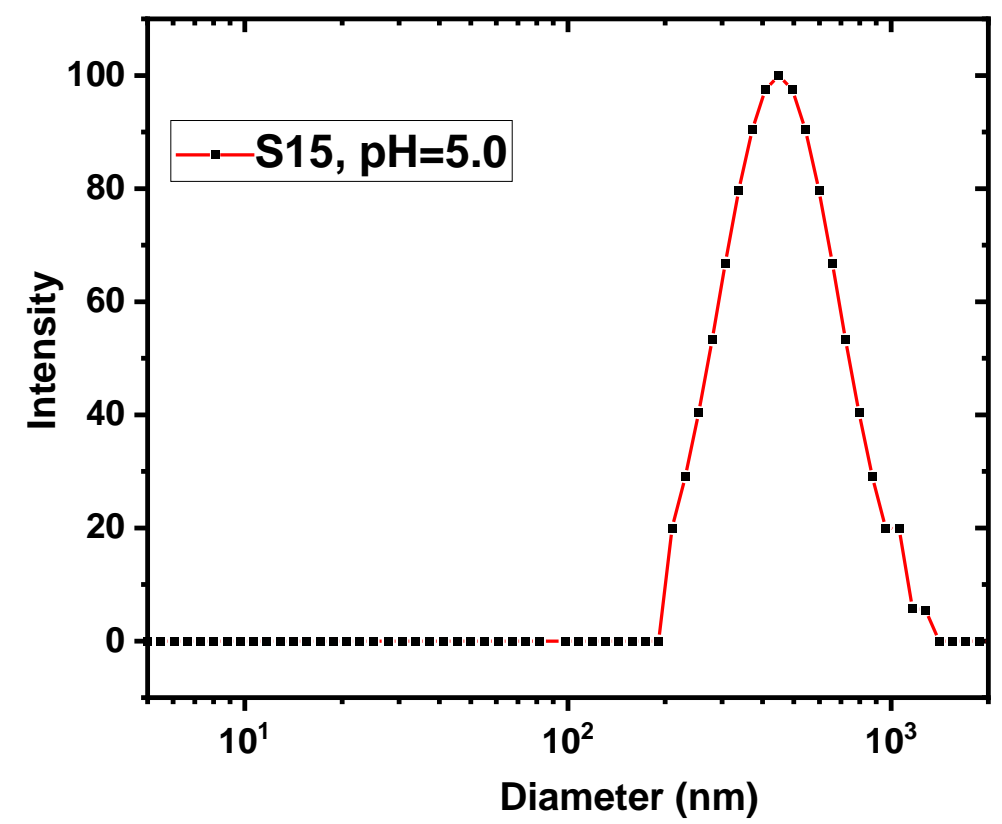

Figure S23: DLS size distribution at $90^{\circ}$ scattering angle of aggregates formed by the polymer $\mathrm{S} 15$ at $\mathrm{pH}=5.0$. 


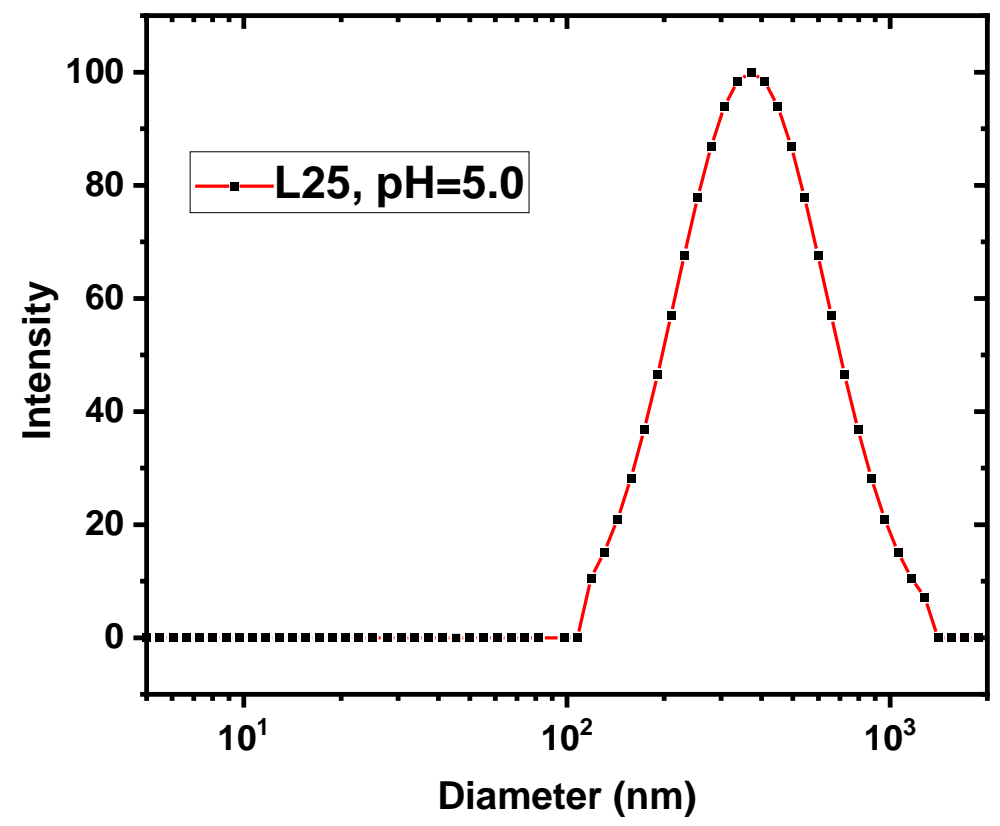

Figure S24: DLS size distribution at $90^{\circ}$ scattering angle of aggregates formed by the polymer $\mathrm{L} 25$ at $\mathrm{pH}=5.0$.

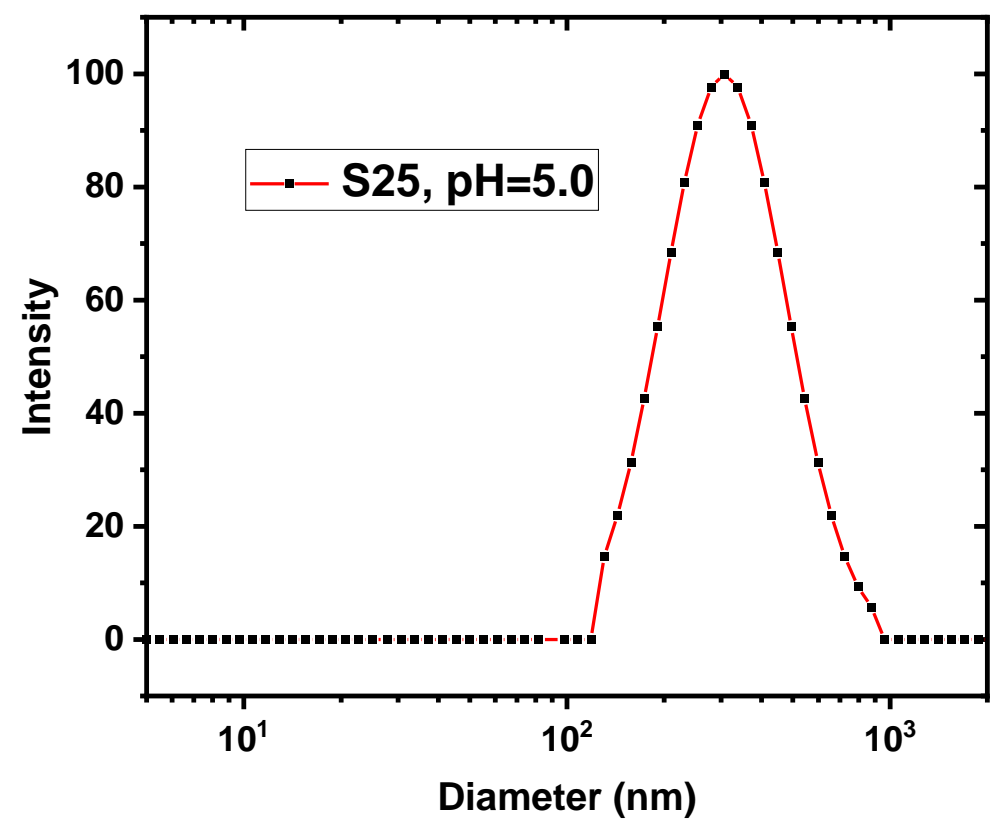

Figure S25: DLS size distribution at $90^{\circ}$ scattering angle of aggregates formed by the polymer $\mathrm{S} 25$ at $\mathrm{pH}=5.0$. 


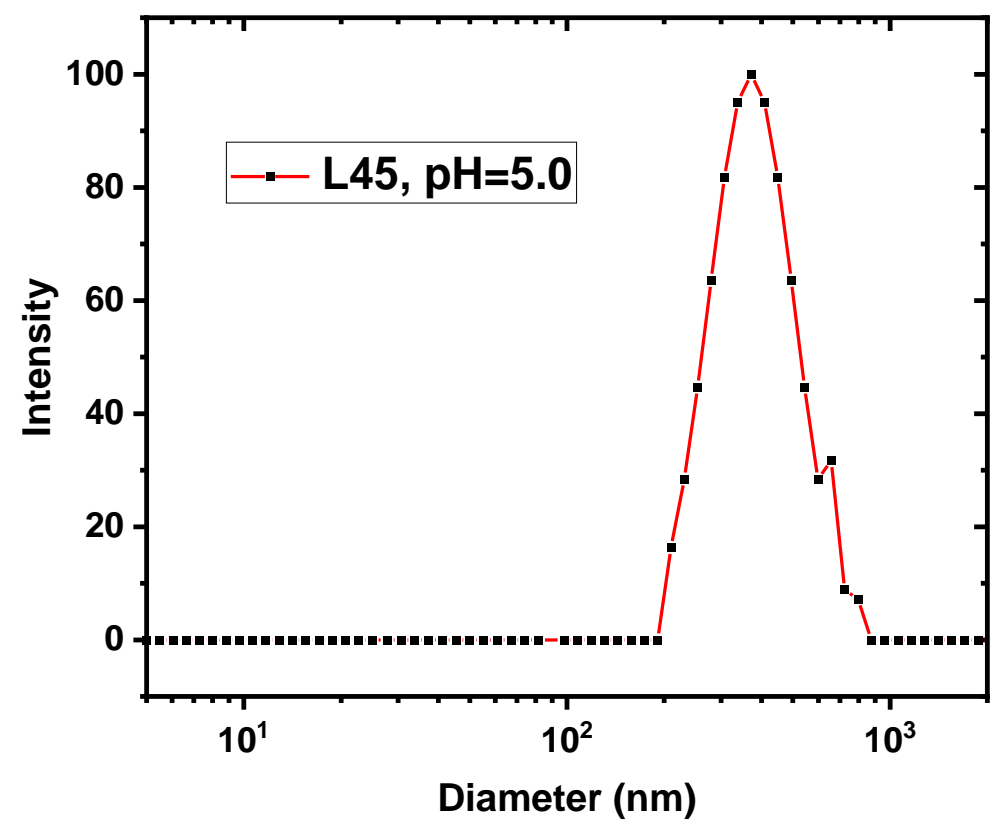

Figure S26: DLS size distribution at $90^{\circ}$ scattering angle of aggregates formed by the polymer $\mathrm{L} 45$ at $\mathrm{pH}=5.0$.

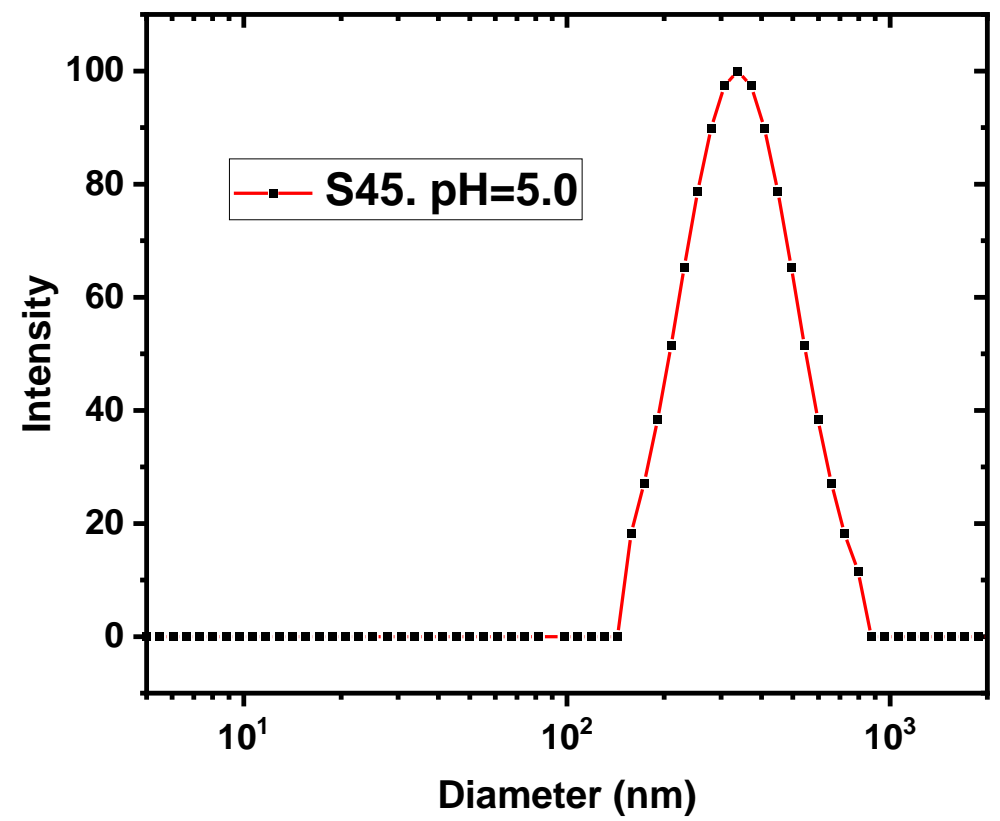

Figure S27: DLS size distribution at $90^{\circ}$ scattering angle of aggregates formed by the polymer $\mathrm{S} 45$ at $\mathrm{pH}=5.0$. 


\section{References.}

(1) Mavrogiorgis, D.; Bilalis, P.; Karatzas, A.; Skoulas, D.; Fotinogiannopoulou, G.; Iatrou, H. Controlled polymerization of histidine and synthesis of well-defined stimuli responsive polymers. Elucidation of the structure-aggregation relationship of this highly multifunctional material. Polym. Chem. 2014, 5 (21), 6256.

(2) Hanski, S.; Houbenov, N.; Ruokolainen, J.; Chondronicola, D.; Iatrou, H.; Hadjichristidis, N.; Ikkala, O. Hierarchical Ionic Self-Assembly of Rod-Comb Block Copolypeptide-Surfactant Complexes. Biomacromolecules 2006, 7 (12), 3379.

(3) Hadjichristidis, N.; Iatrou, H.; Pispas, S.; Pitsikalis, M. Anionic polymerization: High vacuum techniques. Journal of Polymer Science Part a-Polymer Chemistry 2000, 38 (18), 3211.

(4) Hadjichristidis, N.; Iatrou, H.; Pitsikalis, M.; Sakellariou, G. Synthesis of Well-Defined Polypeptide-Based Materials via the Ring-Opening Polymerization of alpha-Amino Acid N-Carboxyanhydrides. Chemical Reviews 2009, 109 (11), 5528. 